Check for updates

Cite this: RSC Adv., 2019, 9, 17658

Received 19th March 2019

Accepted 21st May 2019

DOI: 10.1039/c9ra02108f

rsc.li/rsc-advances

\section{A new way to improve the light-fastness of azo reactive dyes through the introduction of benzene sulfonamide derivatives into the triazine ring}

\begin{abstract}
Xiong Wei, Ma Wei and Zhang Shufen (1D) *
Herein, a new kind of hetero-bifunctional reactive dyes with high light-fastness was designed and synthesized by introducing benzene sulfonamide and its derivatives into the triazine ring. Benzene sulfonamide or its derivatives and 2-amino-5-naphthol-7-sulfonic acid (J-acid) were condensed with cyanuric chloride to synthesize coupling components, which were then coupled with the diazo salt of 4( $\beta$-sulfatoethylsulfonyl)aniline. The dyes were characterized by IR spectroscopy and MS. The color fastness test proved that the light-fastness of the dyes could be improved by 1 grade via the introduction of benzene sulfonamide derivatives into the triazine ring when compared with the case of the control dyes. Fluorescence spectra demonstrated that after the introduction of benzene sulfonamide derivatives, the dye molecule could return to the ground state from the excited state and emit fluorescence; in addition, the introduced benzene sulfonamide derivatives helped to deteriorate the adverse effect of UV light on the dye. Moreover, the dyeing results showed that the dyes containing the sulfonamide groups had equal dyeing properties when compared with that of the control dyes.
\end{abstract}

\section{Introduction}

Reactive dyes exhibit good wet-fastness because they form chemical bonds with the textile fibre. ${ }^{1,2}$ Since the average fixation of mono-functional reactive dyes is below $65 \%,{ }^{3,4}$ reactive dyes are usually designed as bi-functional or multi-functional structures to increase their utilization. ${ }^{5}$ Hetero-bifunctional reactive dyes are widely used due to their good wet-fastness under both acidic and alkali conditions. ${ }^{6,7}$

Due to its brilliant color, abundant hues, simple synthesis procedures, excellent structure diversity and high molar extinction coefficients, the azo chromophore has become the most widely used chromophore. More than $80 \%$ of chromophores used in reactive dyes are azo chromophores. ${ }^{8}$ However, under natural conditions, the azo group will slowly decompose in the presence of moisture, UV light, ozone, etc. ${ }^{9-12}$ With the decomposition of the azo group, the light-fastness of the azo dyes rapidly decreases. Therefore, the development of a strategy to improve the light-fastness of azo dyes is of great importance and current interest. Generally, there are two ways to improve the light-fastness of azo dyes: first, the use of chromophores, such as anthraquinone and metal azo complexes, with high light-fastness, ${ }^{13-15}$ and second, the incorporation of $\mathrm{UV}$ absorbers into the dye molecules or the treatment of textiles with UV absorbers before or after dyeing. ${ }^{16-22} \mathrm{UV}$ absorbers are

State Key Laboratory of Fine Chemicals, Dalian University of Technology, Dalian 116012, P. R. China. E-mail: zhangshf@dlut.edu.cn; Fax: +86 411 84986264; Tel: +8641184986265 usually introduced into a dye molecule by linkage with cyanuric chloride,${ }^{17}$ and the latter also acts as a reactive group in a reactive dye.

The photofading process of azo dyes occurs when the dye molecule is excited from the ground state to the excited state via the absorption of a photon, and then, the dye molecule in the excited state can react with oxygen, ${ }^{23-25}$ the return of the dye molecule to the ground state from the excited state is favourable for the light-fastness of azo dyes. The dye molecule can return to the ground state from the excited state by emitting light; this phenomenon is known as fluorescence.

To date, no studies have been reported on the introduction of a sulfonamide group directly into the $s$-triazine ring in the dye industry to improve the light-fastness of azo dyes. Moreover, significant attention has been focused on the incorporation of $\beta$-sulfatoethylsulfonyl aniline into dyes to improve the affinity and fixation of dyes; ${ }^{26,27}$ in previous studies, the sulfonamide group has also been introduced into dyes as a linkage group to replace benzidine since benzidine is highly carcinogenic and mutagenic. ${ }^{28-32}$

Due to their simplest structure containing a sulfonamide group, herein, benzene sulfonamide and its derivatives were directly incorporated into the s-triazine ring with the aim to obtain a new kind of reactive dyes with high light-fastness. The new kinds of dyes were synthesized using 4-( $\beta$-sulfatoethylsulfonyl) aniline as the diazo component. The coupling component was synthesized by condensing cyanuric chloride with benzene sulfonamide or its derivatives and 2-amino-5naphthol-7-sulfonic acid (J-acid). The influence of benzene 
sulfonamide and its derivatives on the light-fastness has been discussed, and the dyeing properties have also been tested.

\section{Experiment}

\section{Materials and instruments}

2-Amino-5-naphthol-7-sulfonic acid (J-acid) and 4-( $\beta$-sulfatoethylsulfonyl) aniline (para ester) were obtained from Zhejiang Shunlong Chemical Co. Cyanuric chloride and benzene sulfonamide and its derivatives were purchased from Aladdin Industrial Corp. Aniline and sulfanilic acid were bought from Tianjin Guangfu Chemical Reagent Co. All the other chemicals involved in this study were of chemical grade. All the materials were used without further purification.

The FTIR spectra were obtained via the JASCO 430 spectrometer (JASCO, Japan) using KBr pellets. The API-ES-Mass spectra were obtained using the HP1100 mass spectrometer (Hewlett-Packard, USA). UV-Vis spectra were obtained using the HP-8453 UV-Visible spectrometer (Hewlett-Packard, USA). Cotton dyeing was operated using an XW-PDR (Jinjiang Xinwang Dyeing \& Finishing Machinery Factory). Fluorescence spectra were acquired using the F-7000 fluorescence spectrometer (HITACHI, Japan).

\section{Synthesis of dyes}

The synthesis of the mono-azo reactive dyes 3a-i based on J-acid with the substitution of benzene sulfonamide or its derivatives is depicted in Scheme 1 . The synthetic procedure of the dye $\mathbf{3 a}$ is described as below.

(1) Condensation. Cyanuric chloride $(1.84 \mathrm{~g}, 0.01 \mathrm{~mol}$, dissolved in $20 \mathrm{~mL}$ acetone) was dropped to a cooled mixture of benzene sulfonamide $(3.14 \mathrm{~g}, 0.02 \mathrm{~mol}), 0.02 \mathrm{~mol} \mathrm{NaOH}$ and $20 \mathrm{~mL} \mathrm{H}_{2} \mathrm{O}$. The dropping procedure lasted for about $0.5-1$ hour at $0-5{ }^{\circ} \mathrm{C}$. The condensation reaction mixture was stirred for another 1 hour until no cyanuric chloride was detected. Moreover, the excess benzene sulfonamide was filtered after being acidified with the condensation product by adjusting its $\mathrm{pH}$ to lower than 3 using hydrochloric acid. The filtrate was then added to a well-stirred solution of J-acid $(2.39 \mathrm{~g}, 0.01 \mathrm{~mol}$, dissolved in $40 \mathrm{~mL} \mathrm{H}_{2} \mathrm{O}$ at $\mathrm{pH} \mathrm{6-7).} \mathrm{The} \mathrm{reaction} \mathrm{was} \mathrm{stirred} \mathrm{for}$ another 3 hours at $25{ }^{\circ} \mathrm{C}$ and $\mathrm{pH} 6-7$. The reaction was monitored by thin layer chromatography (eluent: $n$-butanol/ isopropanol/ethyl acetate $/ \mathrm{H}_{2} \mathrm{O}=2 / 4 / 1 / 3, \mathrm{v} / \mathrm{v}$ ). The condensation product was used for the subsequent coupling reaction.

(2) Diazotization of 4-( $\beta$-sulfatoethylsulfonyl)aniline. Typically, $0.01 \mathrm{~mol} 4$-( $\beta$-sulfatoethylsulfonyl)aniline was dissolved in

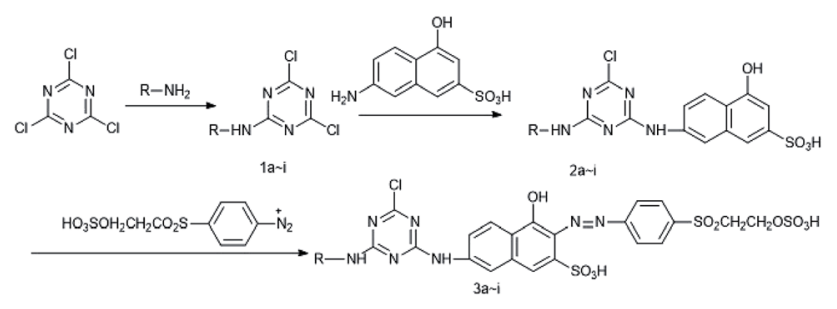

Scheme 1 Synthesis procedure of the reactive dyes $3 a-i$.
$20 \mathrm{~mL}_{2} \mathrm{O}$ at $\mathrm{pH} 6-7$ by adding a sodium carbonate $(10 \%$, w/v) solution followed by cooling to $0-5{ }^{\circ} \mathrm{C}$. A solution of sodium nitrite $(0.72 \mathrm{~g}, 0.0105 \mathrm{~mol})$ in $\mathrm{H}_{2} \mathrm{O}(5 \mathrm{~mL})$ was then added to the solution of 4 -( $\beta$-sulfatoethylsulfonyl)aniline. The mixture was then added to a cooled mixture of ice cubes and concentrated hydrochloric acid $(37 \%, 2.5 \mathrm{~mL}, 0.015 \mathrm{~mol})$ under vigorous stirring. The stirring was continued for $0.5 \mathrm{~h}$ at $0-5{ }^{\circ} \mathrm{C}$ with a positive test for nitrous acid. The excess nitrous acid was decomposed by adding a small amount of sulfamic acid. The diazo salt was used for the subsequent coupling reaction.

(3) Coupling reaction. The diazonium salt was slowly added to the well-stirred condensation product solution prepared previously at $5-10{ }^{\circ} \mathrm{C}$. The reaction $\mathrm{pH}$ was maintained at $7-8$ by adding a $10 \%(\mathrm{w} / \mathrm{v}) \mathrm{Na}_{2} \mathrm{CO}_{3}$ solution, and stirring was maintained for another 1 hour after the solution was completely added. At the completion of the coupling reaction, the dye was salted out by adding potassium acetate, then filtered and washed with ethanol to get dye 3 a.

3a: yield: $83.1 \%$. IR $\left(\mathrm{KBr}, \mathrm{cm}^{-1}\right): 3448(\mathrm{~N}-\mathrm{H}, \mathrm{O}-\mathrm{H}), 2975(\mathrm{C}-$ $\mathrm{H}), 1594(\mathrm{~N}-\mathrm{H}), 1545(\mathrm{~N}=\mathrm{N}), 1498$ (triazine), 1390, $1137\left(\mathrm{SO}_{2}^{-}\right.$ $\mathrm{NH}), 1195,1083\left(-\mathrm{SO}_{3} \mathrm{H}\right) . \mathrm{M} / \mathrm{S}$ (ES-API): $m / z=798.9$, found 798.0 $\left([\mathrm{M}-\mathrm{H}]^{-}\right), 398.5\left([\mathrm{M}-2 \mathrm{H}]^{2-} / 2\right)$.

The dyes $\mathbf{3 b}-\mathbf{g}$ were synthesized via the same way by simply changing the condensation reactant.

Dye $\mathbf{3 b}$ was synthesized by replacing benzene sulfonamide with 4-sulfamoyl benzoic acid. Yield: $103.4 \%$. IR $\left(\mathrm{KBr}, \mathrm{cm}^{-1}\right)$ : $3429(\mathrm{~N}-\mathrm{H}, \mathrm{O}-\mathrm{H}), 2975(\mathrm{C}-\mathrm{H}), 1596(\mathrm{~N}-\mathrm{H}), 1561(\mathrm{~N}=\mathrm{N}), 1499$ (triazine), $1453(\mathrm{O}-\mathrm{H}), 1385,1137\left(\mathrm{SO}_{2}-\mathrm{NH}\right), 1257,1051$ $\left(-\mathrm{SO}_{3} \mathrm{H}\right) . \mathrm{M} / \mathrm{S}$ (ES-API): $\mathrm{m} / \mathrm{z}=842.98$, found $842.0\left([\mathrm{M}-\mathrm{H}]^{-}\right)$, $420.6\left([\mathrm{M}-2 \mathrm{H}]^{2-} / 2\right)$.

Dye $3 \mathbf{c}$ was obtained by replacing benzene sulfonamide with 4-toluene sulfonamide. Yield: $88.6 \%$. IR $\left(\mathrm{KBr}, \mathrm{cm}^{-1}\right): 3463(\mathrm{~N}-$ $\mathrm{H}, \mathrm{O}-\mathrm{H}), 2978(\mathrm{C}-\mathrm{H}), 1595(\mathrm{~N}-\mathrm{H}), 1556(\mathrm{~N}=\mathrm{N}), 1498$ (triazine), 1451, $1390(\mathrm{C}-\mathrm{H}), 1320,1137\left(\mathrm{SO}_{2}-\mathrm{NH}\right), 1221,1052\left(-\mathrm{SO}_{3} \mathrm{H}\right) . \mathrm{M} /$ S (ES-API): $m / z=813.0$, found $811.8\left([\mathrm{M}-\mathrm{H}]^{-}\right), 405.5$ ([M $\left.2 \mathrm{H}]^{2-} / 2\right)$.

Dye 3d was synthesized by replacing benzene sulfonamide with 4-trifluoromethyl benzene sulfonamide. Yield: $72.2 \%$. IR $\left(\mathrm{KBr}, \mathrm{cm}^{-1}\right): 3444(\mathrm{~N}-\mathrm{H}, \mathrm{O}-\mathrm{H}), 2976(\mathrm{C}-\mathrm{H}), 1595(\mathrm{~N}-\mathrm{H}), 1543$ $(\mathrm{N}=\mathrm{N}), 1499$ (triazine), 1324, 1189, $1168\left(\mathrm{Ar}-\mathrm{CF}_{3}\right), 1390,1136$ $\left(\mathrm{SO}_{2}-\mathrm{NH}\right), 1225,1051\left(-\mathrm{SO}_{3} \mathrm{H}\right) . \mathrm{M} / \mathrm{S}$ (ES-API): $\mathrm{m} / \mathrm{z}=866.9$, found $865.9\left([\mathrm{M}-\mathrm{H}]^{-}\right), 432.5\left([\mathrm{M}-2 \mathrm{H}]^{2-} / 2\right)$.

Dye 3e was obtained by replacing benzene sulfonamide with 4-nitrobenzene sulfonamide. Yield: $77.5 \%$. IR $\left(\mathrm{KBr}, \mathrm{cm}^{-1}\right): 3442$ $(\mathrm{N}-\mathrm{H}, \mathrm{O}-\mathrm{H}), 2975(\mathrm{C}-\mathrm{H}), 1594(\mathrm{~N}-\mathrm{H}), 1564(\mathrm{~N}=\mathrm{N}), 1529,1355$ $\left(-\mathrm{NO}_{2}\right), 1498$ (triazine), 1385, $1138 \quad\left(\mathrm{SO}_{2}-\mathrm{NH}\right), 1226,1052$ $\left(-\mathrm{SO}_{3} \mathrm{H}\right) . \mathrm{M} / \mathrm{S}$ (ES-API): $m / z=843.9$, found $842.9\left([\mathrm{M}-\mathrm{H}]^{-}\right)$, $421.0\left([\mathrm{M}-2 \mathrm{H}]^{2-} / 2\right)$.

Dye 3f was synthesized by replacing benzene sulfonamide with 4-chlorobenzene sulfonamide. Yield: $89.6 \%$. IR $\left(\mathrm{KBr}, \mathrm{cm}^{-1}\right): 3406(\mathrm{~N}-\mathrm{H}, \mathrm{O}-\mathrm{H}), 2978(\mathrm{C}-\mathrm{H}), 1595(\mathrm{~N}-\mathrm{H}), 1542$ $(\mathrm{N}=\mathrm{N}), 1498$ (triazine), 1386, $1136\left(\mathrm{SO}_{2}-\mathrm{NH}\right), 1257,1050$ $\left(-\mathrm{SO}_{3} \mathrm{H}\right), 1087$ ( $\left.\mathrm{Ar}-\mathrm{Cl}\right)$. M/S (ES-API): $\mathrm{m} / z=832.9$, found 831.8 $\left([\mathrm{M}-\mathrm{H}]^{-}\right), 415.5\left([\mathrm{M}-2 \mathrm{H}]^{2-} / 2\right)$.

Dye $3 \mathbf{g}$ was obtained by replacing benzene sulfonamide with 4-bromobenzene sulfonamide. Yield: $99.4 \%$. IR $\left(\mathrm{KBr}, \mathrm{cm}^{-1}\right)$ : $3422(\mathrm{~N}-\mathrm{H}, \mathrm{O}-\mathrm{H}), 2975(\mathrm{C}-\mathrm{H}), 1595(\mathrm{~N}-\mathrm{H}), 1564(\mathrm{~N}=\mathrm{N}), 1498$ 
(triazine), 1388, $1137\left(\mathrm{SO}_{2}-\mathrm{NH}\right), 1221,1051\left(-\mathrm{SO}_{3} \mathrm{H}\right), 1078(\mathrm{Ar}-$ $\mathrm{Br}) . \mathrm{M} / \mathrm{S}$ (ES-API): $m / z=876.9$, found $437.5\left([\mathrm{M}-2 \mathrm{H}]^{2-} / 2\right)$.

\section{Synthesis of control dyes $\mathbf{3 h}-\mathbf{i}$}

The synthesis procedure for control dye $\mathbf{3 h}$ is described below.

Cyanuric chloride $(1.92 \mathrm{~g}, 0.0105 \mathrm{~mol})$ and $20 \mathrm{~g}$ of ice cubes were stirred for 30 minutes at $0-5{ }^{\circ} \mathrm{C}$. The first condensation reaction was started by adding aniline $(0.93 \mathrm{~g}, 0.01 \mathrm{~mol})$ at the temperature of $0-5{ }^{\circ} \mathrm{C}$ for 2 hours. Then, the condensation mixture was added to J-acid $(2.39 \mathrm{~g}, 0.01 \mathrm{~mol})$ at the temperature of $30{ }^{\circ} \mathrm{C}$ and $\mathrm{pH}$ of $6-7$. The reaction was monitored by TLC (eluent: $n$-butanol/isopropanol/ethyl acetate $/ \mathrm{H}_{2} \mathrm{O}=2 / 4 / 1 / 3 ; \mathrm{v} / \mathrm{v}$ ). The diazotization and coupling process were the same as those of dye 3a.

3h: yield: 84.4\%. IR (KBr, cm $\left.{ }^{-1}\right): 3397(\mathrm{~N}-\mathrm{H}, \mathrm{O}-\mathrm{H}), 2976(\mathrm{C}-$ $\mathrm{H}), 1599(\mathrm{~N}-\mathrm{H}), 1575(\mathrm{~N}=\mathrm{N}), 1496$ (triazine), $1298(\mathrm{C}-\mathrm{N}), 1255$ (C-O), 1227, 1049 (-SO $\left.\mathrm{SO}_{3} \mathrm{H}\right) . \mathrm{M} / \mathrm{S}$ (ES-API): $m / z=735.03$, found $734.0\left([\mathrm{M}-\mathrm{H}]^{-}\right), 366.5\left([\mathrm{M}-2 \mathrm{H}]^{2-} / 2\right)$.

3i was synthesized using sulfanilic acid instead of aniline. Yield: $82.0 \%$. IR (KBr, cm $\left.{ }^{-1}\right): 3443(\mathrm{~N}-\mathrm{H}, \mathrm{O}-\mathrm{H}), 2973(\mathrm{C}-\mathrm{H})$, $1596(\mathrm{~N}-\mathrm{H}), 1557(\mathrm{~N}=\mathrm{N}), 1495$ (triazine), $1370(\mathrm{C}-\mathrm{N}), 1222,1050$ $\left(-\mathrm{SO}_{3} \mathrm{H}\right) . \mathrm{M} / \mathrm{S}$ (ES-API): $m / z=814.98$, found $406.5\left([\mathrm{M}-2 \mathrm{H}]^{2-}\right.$ / 2).

\section{Dyeing process}

The dyes 3a-i were applied to the dyeing cotton at $1-2 \%$ owf color shade to achieve dyeing cotton with a similar $K / S$ value at $\mathrm{Na}_{2} \mathrm{SO}_{4}$ of $100 \mathrm{~g} \mathrm{~L}^{-1}$ (added in three times) and $\mathrm{Na}_{2} \mathrm{CO}_{3}$ of $10 \mathrm{~g}$ $\mathrm{L}^{-1}$ under the fixation of $75{ }^{\circ} \mathrm{C}$. The liquor-to-goods ratio was 10 : 1. After dyeing, the colored cotton was washed thoroughly; then, the dyeing cotton was soaped in a $2 \mathrm{~g} \mathrm{~L}^{-1} \mathrm{OP}-10$ solution at $95{ }^{\circ} \mathrm{C}$ for $10 \mathrm{~min}$ and finally washed and dried. The dyeing process was conducted as descripted in Fig. 1.

The exhaustion, fixation and reactivity of the dyes were calculated using eqn (1)-(3), and the absorbance was determined using the HP $8453 \mathrm{UV}$-Vis spectrophotometer at the $\lambda_{\max }$ of each dye.

$$
\begin{gathered}
E=\left(A_{0}-A_{1}\right) / A_{0} \times 100 \% \\
F=\left(A_{0}-A_{1}-A_{2}\right) / A_{0} \times 100 \% \\
R=E / F \times 100 \%
\end{gathered}
$$

where $A_{0}, A_{1}$ and $A_{2}$ respectively represent the absorbance of the original dyeing solution, the dyeing waste solution and the soaped solution.

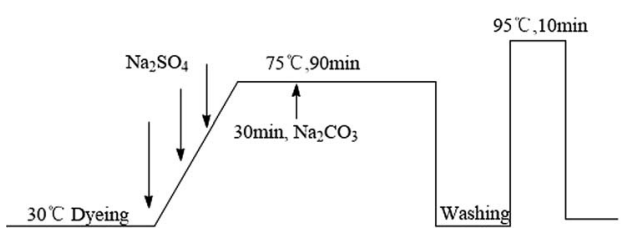

Fig. 1 Dyeing procedure of the synthesized dyes.

\section{Color fastness measurement}

The wash fastness was assessed using a $5 \mathrm{~g} \mathrm{~L}^{-1}$ standard soap solution at $40{ }^{\circ} \mathrm{C}$ for $30 \mathrm{~min}$ according to $\mathrm{GB} / \mathrm{T}$ 3921-2008. The rub fastness was tested according to GB/T 3920-2008 using a Y(B)571-II crockmeter (Darong Standard Textile Apparatus Co. Ltd., Wenzhou). The light-fastness was tested according to GB/T 8427-2008 using YG(B)611-V light-fastness tester (Darong Standard Textile Apparatus Co. Ltd. Wenzhou). The $K / S$ value was measured by using a Ultrascan XE Color Measuring and Matching Meter (Hunter Co. UK).

\section{Results and discussion}

\section{Dye synthesis}

In this study, dyes based on J-acid were synthesized, as depicted in Scheme 1. Benzene sulfonamide derivatives were condensed with cyanuric chloride to obtain a new kind of reactive dyes with high light-fastness.

\section{Synthesis of the reactive dyes $3 a-i$}

The reactants $\mathrm{R}-\mathrm{NH}_{2}$ and J-acid were condensed with cyanuric chloride, and then, the obtained product was coupled with a para ester diazo salt to synthesize the dyes $\mathbf{3 a - i}$, as depicted in Scheme 1. Benzene sulfonamide and its derivatives were used to synthesize the dyes $\mathbf{3 a - g}$ containing sulfonamide groups. Dyes substituted with the anilino and 4-sulfonato phenyl groups were used to synthesize the control dyes $3 \mathbf{h}-\mathbf{i}$.

The visible spectra of the dyes $\mathbf{3 a}-\mathbf{i}$ are shown in Fig. 2. As shown in Fig. 2, the dyes 3a-i exhibit same absorption feature in the visible light region due to the presence of same chromophore based on J-acid. All the dyes showed a broad absorption band from 400 to $550 \mathrm{~nm}$, with the maximum absorption wavelength of about $480 \mathrm{~nm}$.

The structural and UV-Vis absorption information of $\mathbf{3 a - i}$ are listed in Table 1 . The molar absorption coefficients range from $19103 \mathrm{~L} \mathrm{~mol}^{-1} \mathrm{~cm}^{-1}$ to $27079 \mathrm{~L} \mathrm{~mol}^{-1} \mathrm{~cm}^{-1}$. Dyes substituted with benzene sulfonamide and its derivatives have higher molar

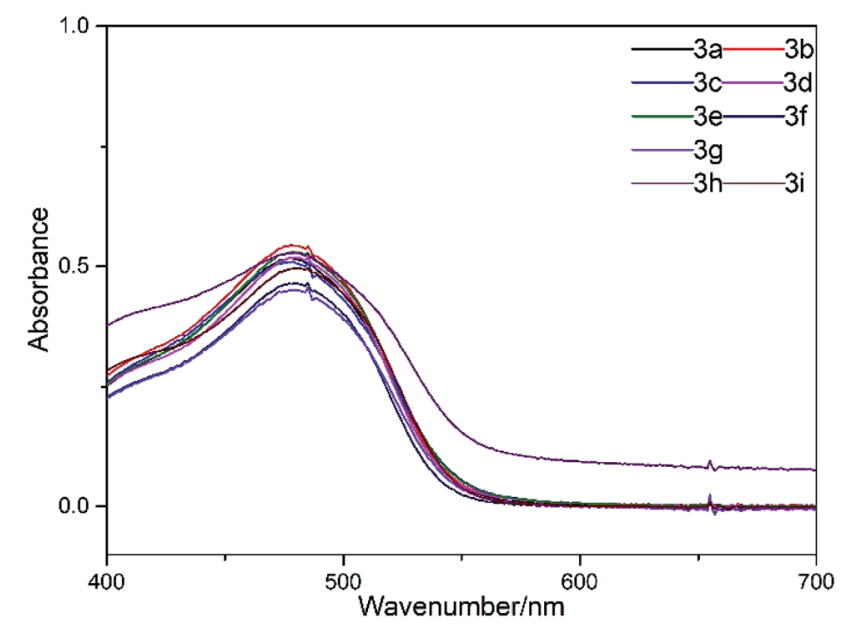

Fig. 2 Visible spectra of the dyes $3 a-i$. 
Table 1 Structure, solubility and spectral data of the dyes 3a-i based on J-acid

\begin{tabular}{|c|c|c|c|c|}
\hline Dye & $\mathrm{R}$ & $S\left(\mathrm{~g} \mathrm{~L}^{-1}\right)$ & $\begin{array}{l}\lambda_{\max } \\
\left(\mathrm{nm}, \mathrm{H}_{2} \mathrm{O}\right)\end{array}$ & $\varepsilon\left(\mathrm{L} \mathrm{mol}^{-1} \mathrm{~cm}^{-1}\right)\left(\mathrm{H}_{2} \mathrm{O}\right)$ \\
\hline $3 a$ & & 140.52 & 478 & 21185 \\
\hline $3 \mathbf{b}$ & & 226.94 & 479 & 21880 \\
\hline $3 \mathbf{c}$ & & 96.16 & 478 & 22598 \\
\hline $3 d$ & & 154.36 & 479 & 25037 \\
\hline $3 \mathbf{e}$ & & 222.58 & 478 & 27079 \\
\hline $3 f$ & & 66.98 & 479 & 25958 \\
\hline $3 g$ & & 67.68 & 479 & 23355 \\
\hline $3 \mathbf{h}$ & & 20.20 & 479 & 19103 \\
\hline $3 \mathbf{i}$ & & 163.18 & 479 & 19947 \\
\hline
\end{tabular}

absorption coefficients than the control dyes $3 \mathbf{h}-\mathbf{i}$. When different substitution groups were incorporated into the dye molecules, the solubility of the dyes $\mathbf{3 a - i}$ significantly differed. The dye $\mathbf{3 h}$ substituted with aniline exhibited the lowest solubility of $20.20 \mathrm{~g} \mathrm{~L}^{-1}$. When another water-soluble group, carboxyl group, was substituted into the dye molecule, $\mathbf{3 b}$ exhibited the highest solubility of $226.94 \mathrm{~g} \mathrm{~L}^{-1}$ among all the dyes.

The incorporation of benzene sulfonamide and its derivatives had a positive effect on the dye solubility; the improved solubility most probably originated due to the increase in molecular polarity, which could help reduce the formation of dye clusters; on the other hand, the increased molecular polarity originated due to the deterioration of molecular planarity, which resulted from the introduction of the sulfonamide group.

\section{Dyeing properties}

The dyeing process was conducted as shown in Fig. 1. The dyes $3 \mathbf{a}-\mathbf{i}$ were applied to the dyeing cotton at $1-2 \%$ omf to achieve the close $K / S$ values of about 15.5-16.5. To reduce the hydrolysis of vinyl sulfonate and enhance the reactivity of the monochlorotriazine reactive group, the fixation temperature was set at $75{ }^{\circ} \mathrm{C}$.

\section{Dyeing results}

The dyeing results for $\mathbf{3 a - i}$ are provided in Table 2. To compare the influence of the sulfonamide group on the dyeing properties of different dyes, the control dyes $3 \mathbf{h}$ and $3 \mathbf{i}$ without the substitution of the sulfonamide group were designed and compared with the dyes 3a-g substituted with benzene
Table 2 Dyeing results of the dyes 3a-i

\begin{tabular}{llll}
\hline Dye & $E \%$ & $F \%$ & $R \%$ \\
\hline 3a & 98.7 & 86.4 & 87.6 \\
3b & 86.7 & 72.0 & 83.1 \\
3c & 96.0 & 82.9 & 86.3 \\
3d & 98.1 & 84.2 & 85.8 \\
3e & 93.9 & 79.9 & 85.0 \\
3f & 96.5 & 79.7 & 82.6 \\
3g & 98.4 & 86.1 & 87.5 \\
3h & 95.7 & 87.7 & 91.7 \\
3i & 95.1 & 87.3 & 91.8
\end{tabular}

sulfonamide and its derivatives. Moreover, Fig. 3 displays the images of the dyeing cotton. As shown in Fig. 3, the dyes 3a-i provide the same orange color, and all the dyeing cotton samples show good color uniformity.

In Table 2, we can see that the exhaustion of the dyes 3a and 3h was $98.7 \%$ and $95.7 \%$, and the fixation was $86.4 \%$ and $87.7 \%$, respectively. The exhaustion and fixation of the dyes $3 \mathbf{a}$ and $3 \mathbf{h}$ were almost the same. The difference in the structures of the dyes $\mathbf{3 a}$ and $3 \mathbf{i}$ originated due to the substitution of the sulfonamide group; however, similar dyeing properties obtained at $75{ }^{\circ} \mathrm{C}$ indicated that the introduction of the sulfonamide group had a slight influence on the dyeing properties. Using another soluble group in the dye molecule, the solubility of the dyes $\mathbf{3} \mathbf{b}$ and $\mathbf{3} \mathbf{i}$ was found to be significantly higher than that of those without the soluble group. Owing to the high solubility of dye $3 \mathbf{b}$ (up to $226.94 \mathrm{~g} \mathrm{~L}^{-1}$ ), its exhaustion was only $86.7 \%$, which was lower than that of the other dyes. Moreover, the presence of the carboxyl group in $3 \mathrm{~b}$ in the form of $-\mathrm{COO}^{-}$ would increase the electrostatic repulsion between the dyes and the cotton fibers. Although it was substituted with another water-soluble group, the dye $3 \mathbf{i}$ still maintained the high exhaustion of $95.1 \%$, which was attributed to its low solubility and high substantivity. The fixation of the dye $3 \mathbf{b}$ was $72.0 \%$, which was lower than that of the dye $3 \mathbf{i}(87.3 \%)$. The fixation difference between $\mathbf{3 b}$ and $\mathbf{3} \mathbf{i}$ was due to the increase in steric hindrance during the fixation reaction caused by the introduction of the sulfonamide group.

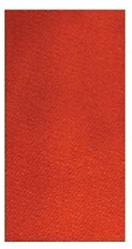

$3 a$

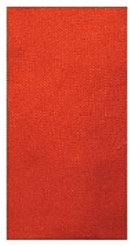

$3 \mathrm{f}$

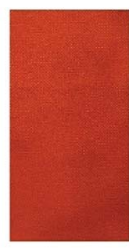

$3 b$

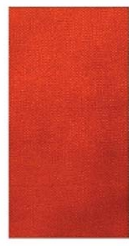

$3 g$

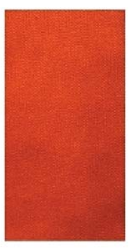

$3 \mathrm{c}$

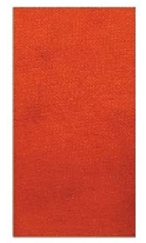

$3 \mathrm{~h}$

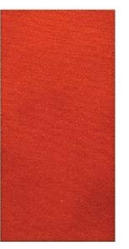

$3 d$

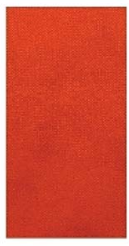

$3 \mathrm{i}$

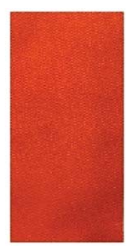

$3 e$
Fig. 3 Images of the cotton dyed with the dyes 3a-i. 
For the dyes $\mathbf{3 c}-\mathbf{g}$ with different substitution groups on the benzene sulfonamide residue, the solubility differed from 66.98 to $222.58 \mathrm{~g} \mathrm{~L}^{-1}$. However, no obvious difference in their exhaustion and fixation was observed; this implied that the substitution groups on the benzene sulfonamide had no essential influence on the dye exhaustion and fixation. The steric hindrance caused by the incorporation of sulfonamide made the reaction between the reactive dyes and cotton difficult to occur; this led to a decrease in the fixation of the dyes $\mathbf{3 c - g}$.

\section{Color fastness of the dyes}

The color fastness of the dyes with similar $K / S$ values on cotton was tested and is presented in Table 3 . Since the covalent bonds formed between the dyes and cotton are the same, the rubfastness and wash-fastness of the dyes involved in this study should be the same. However, because of higher water solubility of dyes due to the introduction of benzene sulfonamide or its derivatives, the color fastness test showed that the rub-fastness and wash-fastness of the dyes $\mathbf{3 a - g}$ containing benzene sulfonamide and its derivatives were slightly better than those of the control dyes $\mathbf{3 h}$ and $\mathbf{3 i}$. The high water-solubility provided the dyes with a good wash-off property, which was favourable to improve the wet-fastness and rub-fastness. Moreover, the lightfastness values of the dyes $\mathbf{3} \mathbf{b}-\mathbf{g}$ containing benzene sulfonamide derivatives were 4-5 grade, which were 1 grade higher than those of the dye $\mathbf{3 a}$ and the control dyes $\mathbf{3 h}$ and $\mathbf{3 i}$. The difference in the light-fastness could be explained by the difference in their fluorescence spectra.

The fluorescence emission spectra of the dyes $\mathbf{3 a - g}$ and control dyes $\mathbf{3 h}$ and $\mathbf{3 i}$ were obtained, as displayed in Fig. 4. All the dyes have been tested at the concentration of $2 \mathrm{~g} \mathrm{~L}^{-1}$, which is about the dyeing concentration. Moreover, the fluorescence intensity of the system has been determined from 350 to $575 \mathrm{~nm}$ with the excitation wavelength of $300 \mathrm{~nm}$ since all the dyes show their maxima absorption around $300 \mathrm{~nm}$ in the UV region.

From Fig. 4, we can conclude that after the substitution of the benzene sulfonamide derivatives, the dyes $\mathbf{3 b} \mathbf{b} \mathbf{g}$ show weak fluorescence emission characteristics, which can help the dye molecule in the excited state to return to the ground state by emitting fluorescence; in addition, the dye 3a shows weaker fluorescence than the dyes $\mathbf{3 b} \mathbf{b} \mathbf{g}$; this weakens the effective

Table 3 Color fastness of dyes $3 a-i$ on cotton

\begin{tabular}{|c|c|c|c|c|c|c|c|}
\hline \multirow[b]{2}{*}{ Entry } & \multirow[b]{2}{*}{$K / S$} & \multirow[b]{2}{*}{ Light-fastness } & \multicolumn{2}{|c|}{$\begin{array}{l}\text { Rub- } \\
\text { fastness }\end{array}$} & \multicolumn{3}{|c|}{ Wet-fastness } \\
\hline & & & Dry & Wet & Change & Cotton & Wool \\
\hline $3 \mathbf{a}$ & 15.66 & $3-4$ & $4-5$ & 4 & $4-5$ & 4 & $4-5$ \\
\hline $3 \mathbf{b}$ & 16.56 & $4-5$ & 4 & 4 & 4 & 4 & $4-5$ \\
\hline $3 c$ & 16.61 & $4-5$ & 4 & 4 & 4 & 4 & $4-5$ \\
\hline $3 d$ & 16.65 & $4-5$ & $4-5$ & 4 & 4 & $4-5$ & $4-5$ \\
\hline $3 \mathbf{e}$ & 15.61 & $4-5$ & $4-5$ & 4 & $4-5$ & 4 & $4-5$ \\
\hline $3 f$ & 16.18 & $4-5$ & $4-5$ & 4 & $4-5$ & 4 & $4-5$ \\
\hline $3 g$ & 16.11 & $4-5$ & $4-5$ & 4 & $4-5$ & 4 & $4-5$ \\
\hline $3 h$ & 15.58 & $3-4$ & 4 & $3-4$ & $4-5$ & 4 & $4-5$ \\
\hline $3 \mathbf{i}$ & 15.98 & $3-4$ & $4-5$ & 4 & 4 & 4 & $4-5$ \\
\hline
\end{tabular}

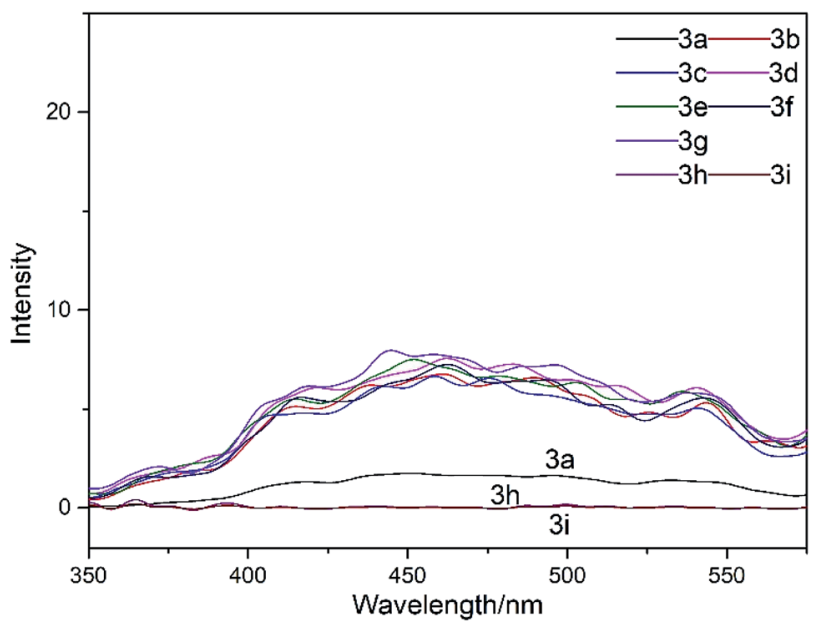

Fig. 4 Fluorescence spectra of the dyes $3 a-i$.

energy transfer of the dye 3a. Moreover, no fluorescence was observed for the dyes $\mathbf{3 h}$ and $\mathbf{3} \mathbf{i}$; this illustrated that the dyes $\mathbf{3 h}$ and $3 \mathbf{i}$ could not return to the ground state from the excited state by emitting fluorescence. Therefore, the differences in the light-fastness of the dyes $\mathbf{3 a - i}$ were most possibly caused by the differences in their fluorescence spectra.

\section{Conclusions}

Herein, benzene sulfonamide and its derivatives were condensed with cyanuric chloride to synthesize a new series of hetero-bifunctional azo dyes; this new kind of dyes was synthesized using 4 -( $\beta$-sulfatoethylsulfonyl) aniline as the diazo component, and the coupling component was synthesized by condensing cyanuric chloride with benzene sulfonamide or its derivatives and J-acid. According to the fastness test, dyes substituted with benzene sulfonamide derivatives displayed better light fastness than the control dyes, which was about 1 grade higher than that of the control dyes. Moreover, the fluorescence spectra showed that after the introduction of the sulfonamide group, the dyes showed weak fluorescence, which could help transfer the UV light. Via the transfer of the absorbed UV light, the destructiveness of the UV light to azo dyes was weakened. Moreover, the dyeing results showed that the incorporation of the sulfonamide group had a little influence on the exhaustion of the dyes; however, the fixation of the dyes decreased as the reaction between the reactive dyes and cotton became difficult to occur due to the increase in the steric hindrance caused by the introduction of sulfonamide groups.

\section{Conflicts of interest}

All authors declare that there are no conflicts of interest.

\section{Acknowledgements}

This work was supported by the National Key R\&D Program of China (2017YFB0307401), the Science Fund for Creative 
Research Groups of the National Natural Science Foundation of China (Grant No. 21421005), Ministry of Education (the Ministry of Education Innovation Team, IRT-13R06) and Dalian University of Technology (Dalian University of Technology Innovative Research Team, DUT2013TB07).

\section{References}

1 D. M. Lewis, Color. Technol., 2014, 130, 382-412.

2 Y. Li, S. Zhang, J. Yang, S. Jiang and Q. Li, Dyes Pigm., 2008, 76, 508-514.

3 J. A. Taylor, Rev. Prog. Color. Relat. Top., 2000, 30, 93-107. 4 P. Kelshaw, J. Soc. Dyers Colour., 1998, 114, 35-36.

5 V. R. Kanetkar, G. S. Shankarling and S. Patil, Colourage, 2000, 47, 35-46.

6 M. Matsui, U. Meyer and H. Zollinger, J. Soc. Dyers Colour., 1988, 104, 425-431.

7 A. A. Mousa, Dyes Pigm., 2007, 75, 747-752.

8 A. Bafana, S. S. Devi and T. Chakrabarti, Environ. Rev., 2011, 19, 350-370.

9 K. Bredereck and C. Schumacher, Dyes Pigm., 1993, 21, 2343.

10 K. Bredereck and C. Schumacher, Dyes Pigm., 1993, 23, 121133.

11 K. Bredereck and C. Schumacher, Dyes Pigm., 1993, 23, 135147.

12 S. N. Batchelor, D. Carr, C. E. Coleman, L. Fairclough and A. Jarvis, Dyes Pigm., 2003, 59, 269-275.

13 A. P. Manian, R. Paul and T. Bechtold, Color. Technol., 2016, 132, 107-113.

14 B. Shan, X. Tong, W. Xiong, W. Qiu, B. Tang, R. Lu, W. Ma, Y. Luo and S. Zhang, Dyes Pigm., 2015, 123, 44-54.
15 A. D. Towns, Dyes Pigm., 1999, 42, 3-28.

16 M. L. Gulrajani, Advances in the dyeing and finishing of technical textiles, 2013, pp. 48-50.

17 R. Rajagopal and S. Seshadri, Dyes Pigm., 1988, 9, 233-241.

18 G. Shabir, A. Saeed, M. Arshad and P. A. Channar, J. Chem. Soc. Pak., 2017, 39, 1017-1028.

19 E. Yousif and R. Haddad, SpringerPlus, 2013, 2, 398.

20 J. C. Paya, P. Diaz-Garcia, I. Montava, P. Miro-Martinez and M. Bonet, J. Ind. Text., 2016, 45, 2-12.

21 Y. Tang, P. Gao, M. Wang, J. Zhu and X. Wan, RSC Adv., 2014, 4, 22617-22620.

22 J.-W. Joo and J. Jang, Fibers Polym., 2018, 19(4), 782-789.

23 C. Chen, B. Zhou, D. Lu and G. Xu, J. Photochem. Photobiol., A, 1995, 89, 25-29.

24 X. Chen, X. Peng, A. Cui, B. Wang, L. Wang and R. Zhang, J. Photochem. Photobiol., A, 2006, 181, 79-85.

25 S. N. Batchelor, D. Carr, C. E. Coleman, L. Fairclough and A. Jarvis, Dyes Pigm., 2003, 59, 269-275.

26 D. M. Lewis and A. A. Siddique, Color. Technol., 2006, 122, 217-226.

27 D. M. Lewis, A. H. Renfrew and A. A. Siddique, Dyes Pigm., 2000, 47, 151-167.

28 W. Li-Min, Chin. J. Struct. Chem., 2007, 26, 6.

29 F. Wang, L. Wang, X. Cai, Y. Sun, L. Su, L. Zhang, Z. Han, G. Zhang and G. Wang, Color. Technol., 2012, 128, 425-433. 30 L. Wang, X. Pan, F. Wang, L. Yang and L. Liu, Dyes Pigm., 2008, 76, 636-645.

31 S. Zhang, Dyes Pigm., 1999, 43, 5.

32 W. Zu-Wang, Chem. Res. Chin. Univ., 2001, 27, 10. 